\title{
Knowledge, Attitude and Practice of Sexuality and Modern Contraceptive Methods among the Young People at Cotonou (Benin)
}

\author{
Tshabu Aguemon Christiane ${ }^{1 *}$, Yunga Foma Jean de Dieu ${ }^{2}$, King Sopouassi V. Nicholas ${ }^{3}$, \\ Matabishi Philemon", Charles Le Bon1, Pérrin René Xavier1 \\ ${ }^{1}$ Faculty of Health Sciences, University of Abomey-Calavi, Cotonou, Benin \\ ${ }^{2}$ Higher Institute of Medical Technology, Uvira, The Democratic Republic of Congo \\ ${ }^{3}$ Redenption Hospital, Monrovia, Sierra Leone \\ ${ }^{4}$ Faculty of Medicine, Bukavu University, Bukavu, The Democratic Republic of Congo \\ Email: *caguemon@yahoo.fr
}

How to cite this paper: Christiane, T.A., de Dieu, Y.F.J., Nicholas, K.S.V., Philemon, M., Le Bon, C. and Xavier, P.R. (2018) Knowledge, Attitude and Practice of Sexuality and Modern Contraceptive Methods among the Young People at Cotonou (Benin). Open Journal of Obstetrics and $G y$ necology, 8, 882-890.

https://doi.org/10.4236/ojog.2018.810091

Received: July 30, 2018

Accepted: August 24, 2018

Published: August 27, 2018

Copyright (c) 2018 by authors and Scientific Research Publishing Inc. This work is licensed under the Creative Commons Attribution International License (CC BY 4.0).

http://creativecommons.org/licenses/by/4.0/

\begin{abstract}
Introduction: Youth is the period of life when one usually experiences sexual relations for the first time. Lack of preparation and inexperience lead to unwanted pregnancies and sexually transmitted infections. The aim was to study the knowledge, attitudes and practices of sexuality and modern contraceptive methods among young people in Cotonou. Method: This was a descriptive and prospective study that was conducted from August to September 2017 among young people living in Cotonou. Results: We had questioned 500 young people. The sex ratio was 0.6 with 267 girls (61.1\%). $27.9 \%$ of young people surveyed do not know the fertility period. $76.2 \%$ of young people are sexually active and $39.8 \%$ have at least 2 sexual partners. Most of these young people had early sexual intercourse at an average age of $16.73 \pm 2.85$ years. Half of the boys have sex for pleasure and half of the girls have sex for love. $100 \%$ of young people know at least one STI, especially HIV/AIDS. Of the $15.10 \%$ of cases of reported pregnancy, $49.2 \%$ resulted in an abortion. $99 \%$ are aware of modern contraceptive methods for the prevention of pregnancy. But $53.7 \%$ are unaware that modern contraceptive methods prevent STIs. The main sources of information on contraception are the media and teachers. The main modern contraceptive method used is the condom in $73 \%$. Young people surveyed do not use modern contraceptive methods in $57.5 \%$. Conclusion: The practices of sexuality and modern contraceptive methods remain quite limited among young people. It is important to intensify information and awareness activities.
\end{abstract}




\section{Keywords}

Young People, Modern Contraceptive Methods, Sexuality

\section{Introduction}

Sex is no longer seen as an instrument of procreation and bonding between families of the same or different community. As a result, we are witnessing the precocity of unprotected sex. This promotes Sexually Transmitted Infections (STIs) and unwanted pregnancies. This is partly the result of a lack of information of young people on the health of the reproduction. According to the demographic health survey carried out in Benin, $13.1 \%$ of girls and $12.9 \%$ of boys have their first sexual intercourse before the age of 15 [1] [2]. In Benin, abortion is one of the main causes of maternal deaths with a case-fatality rate of $17 \%$. These abortions occur in $81 \%$ of cases in young people under 19 years of age with serious or even fatal complications such as $30.6 \%$ of cases of hemorrhage [3] [4] [5]. Similarly, unprotected sex is also at the origin of STIs. In Benin in 2010, the prevalence of STIs was higher among young people in urban areas $(2.3 \%)$ than those in rural areas $(0.3 \%)$ [6]. Contraception becomes the only alternative to overcome these consequences. The lack of information on reproductive health and the lack of knowledge of contraceptive methods are the main factors favoring STIs and unwanted pregnancies. The contraceptive prevalence at the national level is $13 \%$ [7] and 12\%, 5\% in Cotonou [5]. Faced with all these situations, Benin has opted for the health component of adolescents and young people, such as mobilizing for the adoption of responsible sexual behavior, taking charge of reproductive health, family planning and sexual health, awareness of adolescents and young people about the risks and ways of preventing sexually transmitted infections [8]. Despite this, teenagers and young people still have at risk sexual behavior. This has led us to research among young people in Cotonou to better understand their behavior regarding sexuality and contraceptive methods.

Objective: To study the knowledge, attitudes and behavior of young people in the city of Cotonou on sexuality and modern contraceptive methods.

\section{Method and Framework}

It was a descriptive study with prospective data collection. The collection took place from 05 August to 03 September 2017. The study population consisted of young people living in Cotonou. Included in the study were all young people aged between 15 and 24 years of Beninese nationality regardless of sex, present at the place of the survey and having accepted to participate in the study (For young who had between 15 and 18 years, parental consent was sought). Typically, young is a period of life that includes the end of adolescence and the beginning of adulthood, that is, about 15 to 24 years of age [9]. According to modern contraceptive prevalence in Cotonou [1], as the prevalence of young people is 
not known, we have assumed that this prevalence is equal to $12.5 \%$ with a degree of accuracy of $3 \%$, as well as the risk of error. With the Schwartz formula, we have, with a margin of $10 \%$, obtained the sample size between 420 and 514 . We took a size of 500 for our sample. Thus, we performed a 2 degree sampling:

- First degree: Choice of public places. These public places represent the meeting places for young people, rest, meetings and public sport. We made a random draw without surrender of a public square out of 2 in a total lot of 9 public places. This gave us 5 public places: General Mathieu Kerekou Stadium, René Pleven Stadium, Red Star, Hall of Arts and Recreation, Soweto Sports Center.

- Second degree: Choice of young people. We conducted a convenience sampling by systematic recruitment of all youth present at the survey site and meeting the inclusion criteria.

The data was collected using a written, anonymous, pre-coded and tested questionnaire. Collection process: young people were informed about the objectives of the study. The collection was done by 10 interviewers, speaking at least one vernacular, trained for the study. They were divided into 5 binomials or 1 binomial per public place. It was performed every Saturday and Sunday from 07:00 to 18:00. The card was given to the young people who filled it on the spot and gave it to the investigator. For the respondents who do not speak or write French, an interviewer helped them to complete the survey sheets without influencing the respondents' answers. At the end of the filling, another investigator reread the completed questionnaire so that the respondent could check the accuracy of his answers. At the end of each day we check the fact sheets for their validity. The data collected was purified and then analyzed using the computer tool. SPSS 21, Access, Excel 2016 and Word software were used. The data analysis was a descriptive phase that consisted in measuring the frequencies and percentages reached by the different variables. The consent of the respondents was obtained. Anonymity and confidentiality were peremptory.

\section{Results}

Of the 500 questionnaires completed, 63 were poorly completed and eliminated. 437 cards remained, $84.4 \%$ of which were exploited. Profile of the interviewees: the young people were enumerated as follows: 168 (38\%) at the General Mathieu Kerekou stadium, $96(22 \%)$ at the René Pleven stadium, 78 (18\%) at the Soweto sports center, $57(13 \%)$ at the Red Star and $38(9 \%)$ at the Arts and Recreation Hall. There were 267 (61.1\%) female youth and 170 (38.9\%) male sex ratios of 0.6 . The majority (65.2\%) of the youth in our sample were between the ages of 18 and 21, with the extremes of 15 and 24 years old. Of our sample, 399 were in school and 38 were out of school. The majority of 405 (92.7\%) were 245 (91\%) girls and 160 (94.1\%) boys in our sample were single.

Sexuality: Most young people 72.2\% [74.5\% $(\mathrm{n}=199)$ girls and $68.2 \%(\mathrm{n}=$ 166) boys] know the fertility period. Most young people, $89.70 \%$ know that there 
is a risk of pregnancy during the first sexual intercourse. According to the young respondents, the ideal age to have a child is on average $24.29 \pm 2.77$ years, with the majority $74.1 \%$, the desire to make it between 20 and 24 years. For STIs, all young people are aware of HIV, followed by trichomonas (54\%) and gonorrhea (45.53\%) (Table 1). Of the 437-young people surveyed, 333 young people, $76.2 \%$ or $68.90 \%$ of girls and $87.60 \%$ of boys are sexually active. The age of first intercourse among the surveyed youths was $16.73 \pm 2.848$. Half of all female youth (53.1\%) report for love, half young male $(52.3 \%)$ who have it for pleasure (Table 2). $39.8 \%$ (35.6\% of girls and $46.3 \%$ of boys) had multiple sexual partners. Of the respondents, 61 (44 girls and 17 boys) report having ever been pregnant or having a pregnancy, of which $88.6 \%(\mathrm{n}=39)$ girls and $82.4 \%(\mathrm{n}=14)$ said that pregnancies were unwanted. Among pregnancies, $49.2 \%$ (52.3\% for girls and $41.2 \%$ for boys) resulted in induced abortion. The majority $81.4 \%$ of young people (96\% of girls and $68.6 \%$ of boys) had unscheduled sex, of which $33.6 \%$ did so without planning.

Contraception: most young people surveyed 432 (99\%) have already heard about contraception. The sources of information are school (33.1\%), media (22.9\%) and health workers (15.7\%), friends (13.4\%) and parents (7.9\%). The condom is known to all young people (Table 3 ). All young respondents know that contraception prevents pregnancy and $46.3 \%$ know that the condom protects against STIs. The disadvantages of contraceptive methods listed are menstrual cycle disorder (72\%), headaches (53.24\%), weight gain $(26.62 \%)$ and decreased libido (17.6\%). Most $70.3 \%$ (73.4\% of girls and $65.29 \%$ of boys) think that the use of modern contraceptive methods is necessary. 135 (42.5\%) of sexually active young people use contraceptive methods. The most popular modern contraceptive method is condoms (Table 4). Of the 168-young people using contraceptive methods, 42 youth, $25 \%$, do not use modern contraceptive methods. They practice abstinence $(\mathrm{n}=11)$, coitus interruptus $(\mathrm{n}=12)$ and the calendar method $(\mathrm{N}=20)$. Among youth $(\mathrm{n}=269)$ who did not use contraceptive methods, the following reasons were mentioned: side effects $(n=46)$, ignorance of methods $(\mathrm{n}=25)$, shame $(\mathrm{n}=11)$, religion $(\mathrm{n}=10)$, fear of the environment $(\mathrm{n}=24)$, no reason $(\mathrm{n}=153)$.

\section{Discussion}

Young people's knowledge of sexuality. In our series, $72.1 \%$ of respondents were aware of the fertility period. This rate is well above the results of Gnonloufoun (40\%) [7] during his study conducted among high school students in 2015 in the city of Porto-Novo in Benin. It is superimposable to the rate reported by Tsumbu (77\%) in 2015 among women in the market of the city of Cotonou [10]. The knowledge of sexuality is relatively variable depending on the population studied. This explains the high risk of unwanted pregnancies and the risk of contracting an STI. All the youth questioned know or have heard of an STI. Sidibe et al. in Mali [11], Gnonlofoun [7] and Agnoro in Benin [12] found that 
Table 1. Distribution according to the knowledge of STI's.

\begin{tabular}{ccc}
\hline IST & Numbers (n) & Percentage (\%) \\
\hline HIV/AIDS & 437 & 100 \\
Trichomonas & 240 & 54.92 \\
Gonorrhea & 199 & 45.53 \\
Hepatitis B & 76 & 17.40 \\
Syphilis & 38 & 8.70 \\
Chancre pout & 36 & 8.24 \\
Others & 2 & 0.46 \\
\hline
\end{tabular}

${ }^{*}$ Chlamydiosis: 1 ; Herpes: 1 .

Table 2. Distribution by reason of sexual intercourse.

\begin{tabular}{lcccc}
\hline & & \multicolumn{2}{c}{ Gender } & Total \\
\cline { 3 - 4 } & & Female & Male & $\mathrm{N}(\%)$ \\
& For love & $111(53.1)$ & $30(27.5)$ & $141(44.3)$ \\
\cline { 3 - 4 } $\begin{array}{c}\text { Reasons for } \\
\text { sexual }\end{array}$ & By covetousness & $72(34.4)$ & $11(10.9)$ & $83(26.1)$ \\
& Out of curiosity & $5(2.4)$ & $6(5.5)$ & $11(3.46)$ \\
& For pleasure & $14(6.7)$ & $57(52.3)$ & $71(22.3)$ \\
& By constraint & $7(3.5)$ & $4(3.7)$ & $11(1.9)$ \\
& To prove virility & - & $1(0.9)$ & $1(0.31)$ \\
& Total & $209(100)$ & $109(100)$ & $318(100)$ \\
\hline
\end{tabular}

Table 3. Distribution by knowledge of modern contraceptive methods.

\begin{tabular}{ccc}
\hline Type of method & Numbers (n) & Percentage (\%) \\
\hline Condoms & 432 & 100 \\
Injectables & 384 & 88.88 \\
Sterilization & 90 & 20.83 \\
Pills & 151 & 34.95 \\
IUD & 201 & 46.53 \\
Implants & 113 & 26.16 \\
Spermicide & 199 & 46.06 \\
Diaphragm & 25 & 5.78 \\
\hline
\end{tabular}

Table 4. Distribution of modern contraceptive methods used.

\begin{tabular}{ccc}
\hline Modern methods used & Numbers (n) & Percentages (\%) \\
\hline Implant & 8 & 5.9 \\
Injection & 6 & 4.4 \\
Pills & 28 & 20.8 \\
Condoms & 92 & 68.2 \\
IUD & 1 & 0.7 \\
Total & 135 & 100 \\
\hline
\end{tabular}


HIV/AIDS was the most well-known STI with 97.5\%, 93.2\% and 76.92\% respectively. against $100 \%$ in our study. Gonococci is known in $45 \%$ of cases in the study of Sidibé et al. [11] and $44.2 \%$ of cases in the Gnonlofoun study [7]. This rate is identical to ours (45.53\%). The rate of knowledge of HIV/AIDS as the first STI could be justified by the multiple sensitization campaigns on HIV/AIDS in Benin in the last decades since the HIV pandemic in the world.

Young people's knowledge of contraception: the different data on the knowledge of the term of contraception according to the authors, varies from one country to another.

\begin{tabular}{cccc}
\hline Author & Year & Country & $\%$ \\
\hline Banhoro [13] & 2012 & Mali & 90.8 \\
Simbar [14] & 2004 & Iran & 55 \\
Gnonlonfoun [7] & 2015 & Benin & 92 \\
Tsumbu [10] & 2015 & Benin & 80 \\
Agnoro [12] & 2016 & Benin & 10.6 \\
Our Serie & 2017 & Benin & 99 \\
\hline
\end{tabular}

Religious influence in Iran [14] [15] [16] and cultural impact, lack of adequate communication program [12] would influence the level of knowledge about reproductive health. In other studies, however, contraception is known by more than $80 \%$ of the surveyed population. Condoms and pills are the best known among contraceptive methods. Condoms are better known and used because of the multiple campaigns on STIs and HIV/AIDS.

\begin{tabular}{|c|c|c|c|c|c|}
\hline & \multicolumn{4}{|c|}{ Author/Years/Country } & \multirow[b]{2}{*}{$\begin{array}{c}\text { Our serie } \\
2017\end{array}$} \\
\hline & $\begin{array}{c}\text { Banhoro, } \\
\text { 2012, } \\
\text { Burkina-Faso [13] }\end{array}$ & $\begin{array}{c}\text { Tsumbu, } \\
\text { 2015, } \\
\text { Cotonou [10] }\end{array}$ & $\begin{array}{c}\text { Agnoro, } \\
\text { 2016, } \\
\text { Djougou } \\
{[12]}\end{array}$ & $\begin{array}{c}\text { Gnonlonfoun, } \\
2015 \text {, } \\
\text { Porto-novo } \\
{[8]}\end{array}$ & \\
\hline Condoms & $90.8 \%$ & $10.36 \%$ & $39.28 \%$ & $64.9 \%$ & $100 \%$ \\
\hline Pills & $80.6 \%$ & $30.53 \%$ & $28.57 \%$ & $58.6 \%$ & $34.95 \%$ \\
\hline Injectables & $19 \%$ & $19.33 \%$ & - & - & $88.89 \%$ \\
\hline Implants & $39.3 \%$ & $18.77 \%$ & $9.5 \%$ & $4.9 \%$ & $26.16 \%$ \\
\hline IUD & $44.7 \%$ & $12.61 \%$ & - & $7.7 \%$ & $46.53 \%$ \\
\hline Spermicides & - & - & - & - & $46.06 \%$ \\
\hline Sterilization & $4.2 \%$ & - & - & - & $20.83 \%$ \\
\hline
\end{tabular}

All authors [7] [9] [10] [11] [12] [13] and our study found contraceptive methods to be helpful in avoiding unwanted pregnancies and protection against STIs. In our series and in other studies [10] [12], the first place of supply is pharmacy. Family planning centers are not as well known and also less incons- 
picuous. Good communication should be provided to young people so that they can know and enjoy the benefits of being in contact with qualified staff. The sources of information on contraception vary according to the authors:

\begin{tabular}{|c|c|c|c|c|}
\hline & \multicolumn{3}{|c|}{ Authors } & \multirow[b]{2}{*}{$\begin{array}{c}\text { Our serie } \\
2017\end{array}$} \\
\hline & $\begin{array}{l}\text { Ntsumbu, } \\
2015, \\
\text { Cotonou }[10]\end{array}$ & $\begin{array}{c}\text { Gnonlonfoun } \\
2015, \\
\text { Benin [7] }\end{array}$ & $\begin{array}{c}\text { Sidibe } \text { et al., } \\
2006, \\
\text { Bamako in mali [11] }\end{array}$ & \\
\hline Medias & $52.72 \%$ & $39.1 \%$ & $96.3 \%$ & $22.7 \%$ \\
\hline Education & $10.76 \%$ & $32.7 \%$ & $19.6 \%$ & $32.7 \%$ \\
\hline Parents & - & $18.3 \%$ & - & $7.8 \%$ \\
\hline Friends & - & $10 \%$ & $72.4 \%$ & $12.4 \%$ \\
\hline Health worker & $22.73 \%$ & - & - & $15.6 \%$ \\
\hline
\end{tabular}

Young people's attitude towards sexuality: more than half (74.1\%) of our sample are in favor of an age between 20 and 24 to have one child and 6 out of 10 young people disapprove of the practice of induced abortions. For other studies [7] the ideal age is greater than 25 years $(64.6 \%)$ and 8 out of 10 young people disapprove of the practice of induced abortions. In addition, the number of people supporting the fact that abortion is sometimes necessary in our study is almost double $28.8 \%$ compared to $11.4 \%$ [7]. These numbers prove that risky sexual behavior persists in the youth environment.

Young people's attitude towards contraception: contraceptive opinion varies from one country to another and from one region to another, especially under the influence of culture on young people [17] [18] and the information conveyed about contraception. This poor knowledge of contraceptive methods would be the cause of an interest in the use of modern contraceptive methods. It requires the involvement of the community, political authorities and schools for the transmission of good information and the awareness of young people.

Youth Sexuality Practices. In our series, $76.2 \%$ of respondents have already had sex. The rate of sexually active youth is higher for boys (87.6\%) than for girls (68.9\%). Young people have sex more quickly in Cotonou, probably cultural crossings in urban areas and the release of parents on the cultural hold. More than half $(68.6 \%)$ of sexually active young people have had sex between $15-19$ years. This result is similar to that reported by SEPOU et al. in the Central African Republic in 2004 (69.4\%) [19]. this could be explained by the reasons linked to a confusion between friendship and sexual curiosity as well as the low economic level of young people. Thus, there is a high prevalence of unwanted pregnancies [17] [18].

Youth Contraceptive Practices. Half of sexually active youth still use a condom. Except that a significant proportion (33.3\%) of 3 in 10 sexually active youth in our series have unprotected sex. This explains the high risk of occurrence of unwanted pregnancy and sexually transmitted infection in Cotonou. 
The low level of knowledge of the disadvantages, the erroneous information about other contraceptive methods could justify the low use. Hence the need to strengthen communication that takes into account all aspects of contraceptive methods, including the disadvantages and, above all, benefit-oriented, in order to promote better adherence.

\section{Conclusion}

At the end of our descriptive and analytical cross-sectional study of a sample of 500 young people in Cotonou, it appears that much remain to be done in terms of young people's knowledge, attitude and practice on sexuality and modern contraception in Cotonou. Youth education and communication campaigns should be strengthened to improve the reproductive health of young people and adolescents.

\section{Conflict of Interest}

No conflict of interest between the authors, all authors contributed to the development of the article.

\section{References}

[1] INSAE, PNLS, UNICEF, USAID, UNFPA (2007) Demographic and Health Survey III, Benin 2006. National Institute of Statistics and Economic Analysis, Cotonou, 244-257.

[2] Sedgh, G. (2012) Induced Abortion: Incidence and Trends Worldwide from 1995 to 2008. Lancet, 379, 625-632. https://doi.org/10.1016/S0140-6736(11)61786-8

[3] Goyaux, N., Alihonou, E., Diadhiou, F., Leke, R. and Fernand Thonneau, P. (2001) Complications of Induced Abortion and Miscarriage in Three African Countries: A Hospital Based Study among WHO Collaborating Centers. Acta Obstétrica Scandinavica, 80, 568-573. https://doi.org/10.1080/j.1600-0412.2001.080006568.x

[4] Lombat, D.S.A. (2000) Post-Abortion Care at the Cotonou Lagoon Maternity Hospital for 485 Cases of Abortions Recorded at the Cotonou Lagoon Maternity Hospital. Thesis, Abomey-Calavi University, FSS, Cotonou, No. 906.

[5] Alihonou, E., Carre, N., Capochichi, V. and Thonneau, P. (1997) Contraceptive Continuation and Its Déterminants in Benin. Contraception, 55, 97-101. https://doi.org/10.1016/S0010-7824(96)00279-X

[6] Ministry of Public Health, UNFPA (2010) Multisectoral National Strategy for Sexual and Reproductive Health of Adolescents and Youth in Benin 2010-2020. Mother and Child Health Directorate.

[7] Ministry of Health of Benin (2012) Directory of Health Statistics of the Ouémé-Plateau 2011. Services of the Studies of the Planning and Follow-Up of the DDS-OP, Porto Novo.

[8] Gnonlonfoun, S. (2016) Sexuality and Contraception in Two Public High Schools in Porto-Novo. PhD Thesis, University of Porto-Novo, No. 0024/16, 45-70.

[9] Sawyer, S.M., Azzopardi, P.S., Wickremarathne, D. and Patton, G.C. (2018) The Age of Adolescence. The Lancet Child \& Adolescent Health, 2, 223-228. https://doi.org/10.1016/S2352-4642(18)30022-1 
[10] Nguilu Tsumbu, N. (2015) Modern Contraceptive Methods: Knowledge, Attitudes and Practices of Women Traders in the Cotonou Dantokpa Market. Diploma of Specialized Studies in Gynecology and Obstetrics. University of Abomey Calavi, No. 1875.

[11] Sidibe, T., Sangho, H., Traore, M.S., Cisse, M.B., Diallo, B., Keita, M.M., et al. (2006) Knowledge and Practices of High School Students in Bamako Regarding Contraception and Prevention of STIs. Mali Medical, 21, 40-41.

[12] Agnoro, A. (2016) Knowledge, Attitude and Practice of Contraception in School-Based Contraception among Adolescents in Djougou. Memory of DES. University of Abomey Calavi, No. 08, 34-42.

[13] Banhoro, L. (2012) Connaissances, Attitudes and Practices of Contraception in Student Environment of the Public Universities of the City of Ouagadougou (Burkina-Faso). PhD Thesis, University of Ouagadougou, No. 130, 50-72.

[14] Simbar, M., Tehrani, F.R. and Hashemi, Z. (2005) Reproductive Health Knowledge, Attitudes and Practices of Iranian College Students. Health Review of the Eastern Mediterranean, 11, 888-897.

[15] Byamungu, N., Kabinda, J. and Mansuka, T. (2009) Knowledge, Attitudes and Practices of Adolescents in the Bukavu District Health District Regarding Family Planning. Training Center in Reproductive Health/Catholic University of Bukavu, Congo, 98.

[16] Mamadou, B. (2009) Knowledge, Attitudes and Practices of Young People about Contraception Level of Grins. Thesis, Faculty of Medicine and Pharmacy, Dental Association, Bamako, 85.

[17] Akouegninou, A.V. (2006) Knowledge, Attitudes and Practices Regarding Sexuality and Contraception Cotonou. Thesis, University of Abomey-Calavi, FSS, No. 1255.

[18] Oussou, S.M. (2010) Knowledge, Attitudes and Practices Regarding Adolescent Sexuality in School in the City of Porto-Novo. Thesis, Cotonou: University, Abomey-Calavi, FSS, No. 1532.

[19] Sepou, A., Nguembi, E., Yanza, M.C., Ngbal, R. and Nali, M.N. (2004) Sexual Behavior of Students at Bangui University (Central African Republic). Tropical Medicine, 64, 163-167. 